\title{
Construction Sequence Analysis of Tube in Tube Structural System Building
}

\section{U. Leela ${ }^{1} \mid$ G. Janardhan Rao ${ }^{2}$}

${ }^{1}$ PG Scholar, Department of Civil Engineering, Visakha Technical Campus, Andhra Pradesh, India. ${ }^{2}$ Assistant Professor, Department of Civil Engineering, Visakha Technical Campus, Andhra Pradesh, India.

\section{To Cite this Article}

U. Leela and G. Janardhan Rao, "Construction Sequence Analysis of Tube in Tube Structural System Building", International Journal for Modern Trends in Science and Technology, 6(9): 06-12, 2020.

\section{Article Info}

Received on 06-August-2020, Revised on 20-August-2020, Accepted on 25-August-2020, Published on 28-August-2020.

\section{ABSTRACT}

The effect of applying loads sequentially is an important factor and should be considered whileanalyzing multistoried frame structure. It is observed that the effect of the formationsequence increase with the increase in storeys is very important. Therefore, the effect of a construction sequencecannot be neglected and a precise analysis should be conducted.In this paper the construction sequential analysis has been studied on tube in tube structure. For this purpose, a tube in tube structural system building with different heights $(G+35, G+40$, and $G+45)$ has been considered forcomparative study. The plan dimensions of the building are $45 \mathrm{~m} \times 72 \mathrm{~m}$. The structures were modelled and analyzed by using ETABS finite element software.Construction sequence is considered for dead load only. Also, the structure is analyzed for linear static analysis in order to check the stability of the structure as per Indian standards and then the structure is analyzed for construction sequence analysis. The variation in Storey displacements, Column axial forces, bending moments andShear forces were compared to know the construction sequence analysis effect on tube in tube structural system building.

KEYWORDS: Construction sequential analysis, ETABS, High-Rise structure, Tube in Tube structural system

\section{INTRODUCTION}

\section{Tube Structural System:}

The cylinder basic framework is used, to withstand parallel burdens (wind, seismic, sway). The cylinder auxiliary framework structures are developed to perform like an empty pinnacle (for example Cantilevered segment opposite to the surface. This auxiliary framework was introduced by Fazlur Rahman Khan.

\section{Tube in Tube Structural System: -}

It otherwise called hull and core structure. These structures have a center cylinder inside the structure, holding the lift and different administrations, and another cylinder around the outside. The majority of the gravity and horizontal burdens are ordinarily taken by the external cylinder as a result of its more noteworthy quality.

- An external surrounded cylinder along with an inward lift and administration center. The external and internal cylinders act together in opposing both gravity and sidelong stacking in steel-encircled structures. The twisting and cross over shears are upheld three dimensionally at the spine and web surface in the structure.

- The solidness of a surrounded cylinder can likewise be upgraded by utilizing the center to oppose part of the sidelong burden bringing about a cylinder in-tube framework. 
- The floor stomach interfacing the center and the external cylinder move the horizontal burdens to the two frameworks.

- The center itself could be comprised of a strong cylinder, a supported cylinder, or an encircled cylinder. Such a framework is known as a cylinder in-tube.

- It is additionally conceivable to present more than one cylinder inside the border tube.

- The internal cylinder in a cylinder in-tube structure can go about as a second line of safeguard against a vindictive assault with plane or rockets.

\section{Construction Sequence Analysis:}

Over a long period of time the multistoried building frame have been analyzed on the assumption that whole of the load is applied to the completed frame structure with all the loads acting on the building that is self-weight, super imposed load, live load and lateral loads which are applied on the completed frame at a given instant as a single step analysis. But in actual practice the dead load due to each structural component and finishing items are imposed in separate stages as the building frame is constructed story by story in a sequential order. The performance of a building structure with the various load applied in a single step differ significantly from that when the loads are applied in stages. Hence, in order to analyses the structure according to the actual construction practices this is known as construction sequence analysis (CSA). Construction sequence analysis is also known as staged construction analysis which is a nonlinear static form of analysis which takes into account the concept of incremental loading. The structural analysis of multistory buildings is one of the areas that have attracted a great deal of engineering.

\section{Objective of The Present Study:}

> To understand the high-rise structure behavior Analytically during construction at different stages using Construction sequence analysis.

$>$ To study the performance of tube in tube structure during Construction Sequence analysis.

$>$ To know the effect of construction sequence analysis in various structural parameters like deflection, Bending moments, shear force and axial force of the structural elements.
$>$ The Scope of work is limited to detailed analytical study on Construction sequence Analysis of high-rise buildings using ETABS software for three different height of Buildings as $\mathrm{G}+35, \mathrm{G}+40$, and $\mathrm{G}+45$ storied tube in tube structure.

\section{LITERATURE REVIEW}

\section{R. Pranay:}

In this paper two cases have been considered. Whereas in Case 1 the multistoried building (22 storied) with floating columns and transfer girder will be analysed as a whole for the subjected loading and in Case 2 the multistoried building $(22$ storied) with floating columns and transfer girder will be analysed with the reference to the construction sequence or staged construction. A detailed study and comparison of the variation in deformations and forces will be presented for the transfer girders, for the floating column on girders and for the frames which is above transfer girders. The building is analysed and designed using ETABS software.

\section{Geethu Girija Das:}

In this study comparison of conventional analysis with construction stage analysis for a commercial building v15. Comparative Study on Construction Sequence Analysis on Steel Structure without and with Floating Columns by Tin Yadanar Kyaw This study was proposed the building is eleven-storey setback steel structure. Its length was proposed building is $78 \mathrm{ft}$ and width is $66 \mathrm{ft}$. its height was proposed building is $142 \mathrm{ft}$. This building was located in seismic destructive zone V, Mandalay. Its basic wind speed is $80 \mathrm{mph}$. structure is composed of special moment resist frame (SMRF). The Structural elements are designed according to AISC 360-10. Load consideration, stability will check and proposed building are based on ASCE 7-10. The proposed building will analysis and designed with the help of ETABS 2016 version 16.2.1 software. After response spectrum analysis (RSA) has done. Its check stability of it, then the construction sequence analysis (CSA) is considered the structural analysis results of the proposed building are studied such as axial force, shear force and bending moment of the structural frame elements. The effect of floating columns with CSA on axial force for the selected columns of proposed building is more influence from first to sixth floor level. The value of shear force with CSA is abruptly increased at the floated columns level and the 
other level are gradually decreased.

\section{K. Subramanian:}

In the present study, construction sequence analysis is carried out for various lateral load resisting systems such as Special moment resisting frame systems, Shear wall systems and Dual systems. Special cases like SMRF frames with floating columns have also been considered. Three dimensional dynamic analyses have been carried using finite element-based software ETABS. The study reveals the necessity of performing staged analysis as each additional floor creates a significant load upon the columns and the comparison of design forces for each system have been undertaken. It also emphasizes the vulnerability of using floating columns in regions prone to seismic loads.

\section{Kiran Kamath:}

In the present study, a 60-storey 3-D RC frame with core wall at the centre is considered for finding out the shortening of column. The parameter considered to reduce the effect of differential column shortening is the effects of outriggers at different levels under the action of elastic, creep and shrinkage shortening. It was found that the differential column shortening is reduced by $34 \%$ when one outrigger is introduced at the optimum level of $\mathrm{H} / \mathrm{h} 1=1.715$. Along with this optimum position of the outrigger, another outrigger is introduced at different levels to further reduce the differential column shortening and the optimum position of second outrigger is found out that will give the minimum differential column shortening. It was found that second outrigger at $\mathrm{H} / \mathrm{h} 2=1.33$ level reduces the differential shortening by $14 \%$ in addition to that reduced by first outrigger. The present analysis is carried out using a finite element software MIDASGen and by plotting storey height versus differential column shortening between the outer peripheral column and the core wall for different positions of the outriggers.

\section{B Sri Harsha:}

In present paper the main factor which we are considering is Cycle time for floor to floor construction and strength of concrete. Due to architectural requirements some of the columns are designed as floating columns which rests on the transfer girder which intern rests on the shear walls in the multistoried building.

Two cases have been considered for the study and comparison. Whereas in Case 1 the building will be analysed as a whole for the subjected loading (DL, LL, WL, SL) by using ETABS software and in Case 2 the building will be analysed with reference to the construction sequence or staged construction for the subjected loading by using ETABS software.

\section{METHDOLOGY}

In order to observe the Construction sequence analysis effect on the Tube in Tube structure, $\mathrm{G}+35, \mathrm{G}+40$, and $\mathrm{G}+45$ storey building models are considered in this study. The plan dimensions of the building are $45 \mathrm{~m} \times 72 \mathrm{~m}$. This building model is assumed to be located in seismic destructive zone II, Visakhapatnam. The basic wind speed is $50 \mathrm{~m} / \mathrm{sec}$. After Linear static analysis has done for the checking of the stability, then construction sequence analysis (CSA) is considered. The evaluation is carried out by using ETABS software.

The following flow chart describes the Step by step process of present study:

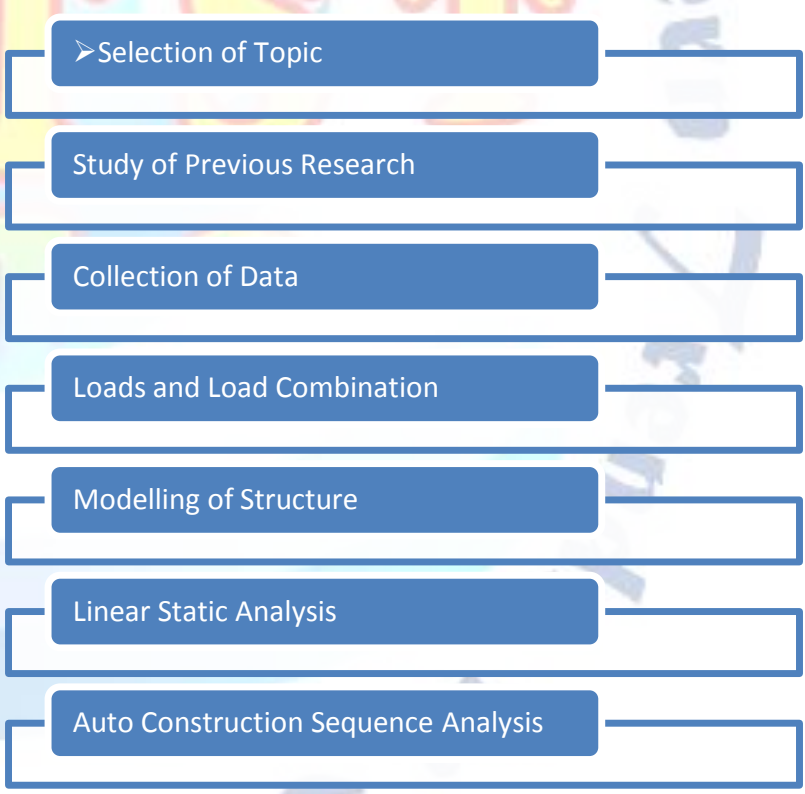

Fig-1: Flow Chart for the Step by Step Process of Present Study

\section{CONSTRUCTION SEQUENCE ANALYSIS OF TUBE IN TUBE STRUCTURE}

Table-1: Primary Data for Analysis

\begin{tabular}{|l|l|}
\hline Description & Specification \\
\hline Story height & $3.0 \mathrm{~m}$ \\
\hline Grade of concrete & M30 \\
\hline
\end{tabular}




\begin{tabular}{|l|l|}
\hline Grade of steel & Fe500 \\
\hline Unit weight of concrete & $25 \mathrm{kN} / \mathrm{m}^{3}$ \\
\hline Floor Finish+ unknown force & $2 \mathrm{kN} / \mathrm{m}^{2}$ \\
\hline Live load & $4 \mathrm{kN} / \mathrm{m}^{2}$ \\
\hline Beam size & ISWB 400 \\
\hline Column size & ISWB 550 \\
\hline Slab Thickness & $200 \mathrm{~mm}$ \\
\hline Zone & II \\
\hline Response reduction factor & 5 \\
\hline Importance factor & 1 \\
\hline Soil type & II \\
\hline
\end{tabular}

In order to observe the Construction sequence analysis effect on $\mathrm{G}+35, \mathrm{G}+40$, and $\mathrm{G}+45$ storey tube in tube structural system building models are considered. This building modelsare assumed to be located in seismic destructive zone II, Visakhapatnam. The basic wind speed is $50 \mathrm{~m} / \mathrm{sec}$. The structure is composed of special moment resisting frame (SMRF). After Linear static analysis has done for the checking of the stability structure according to Indian Standards, then construction sequence analysis (CSA) is considered. The evaluation is carried out by using ETABS software.

\section{V.RESULTS AND DISCUSSION}

After Linear static analysis has done for the checking of the stability structure according to Indian Standards, then construction sequence analysis (CSA) is considered. The evaluation is carried out by using ETABS software. And then, Construction sequence analysis results of the building such as axial force, shear force, bending moment of the structural frame elements and storydisplacement of the structure are presented.

\section{Bending Moment Results of Beams:}

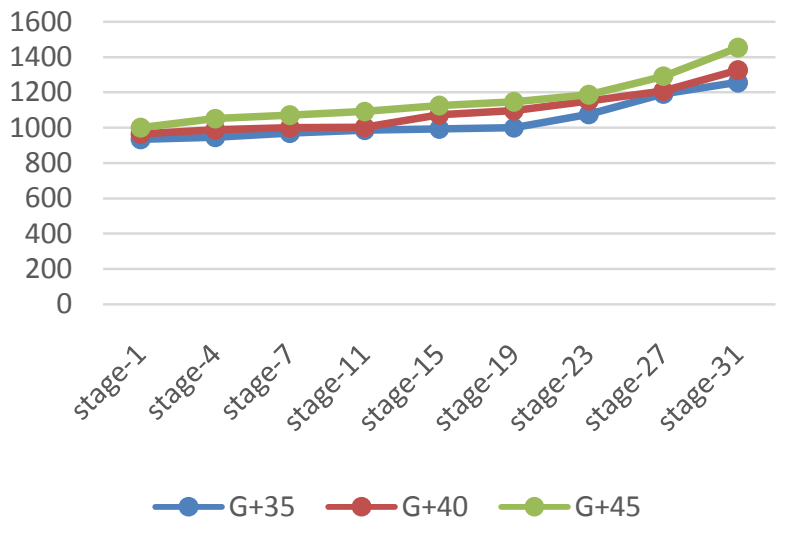

Fig-2: Bending Moment Results of B-5

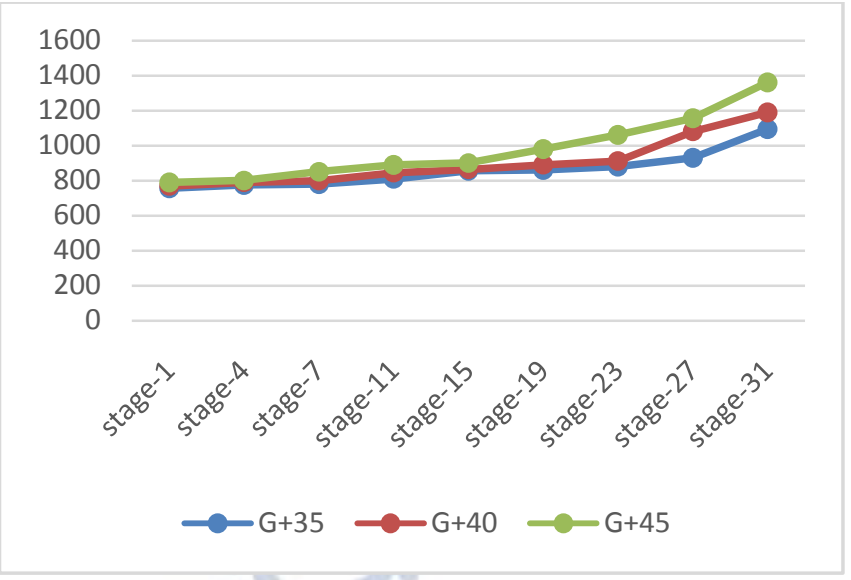

Fig-3: Bending Moment Results of B-13

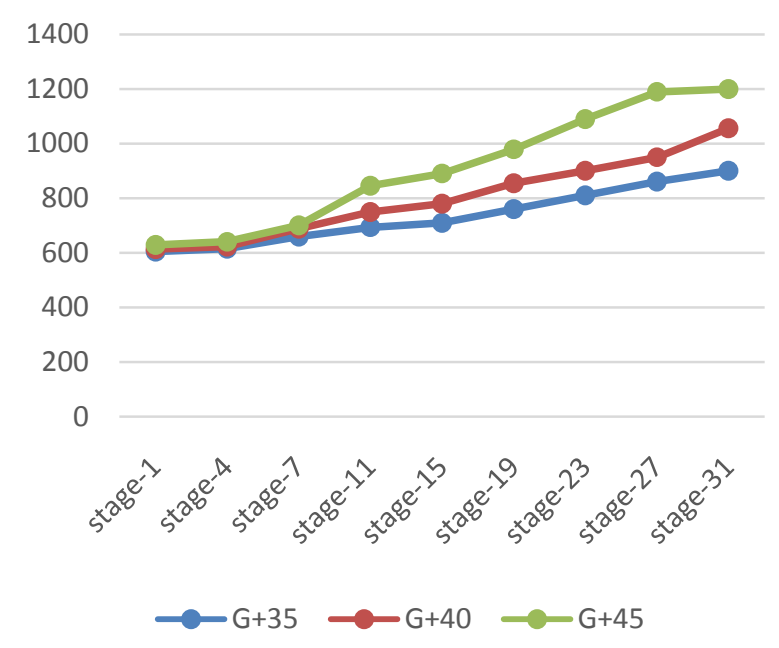

Fig-4: Bending Moment Results of B-24

\section{Shear Force Results of Beams:}

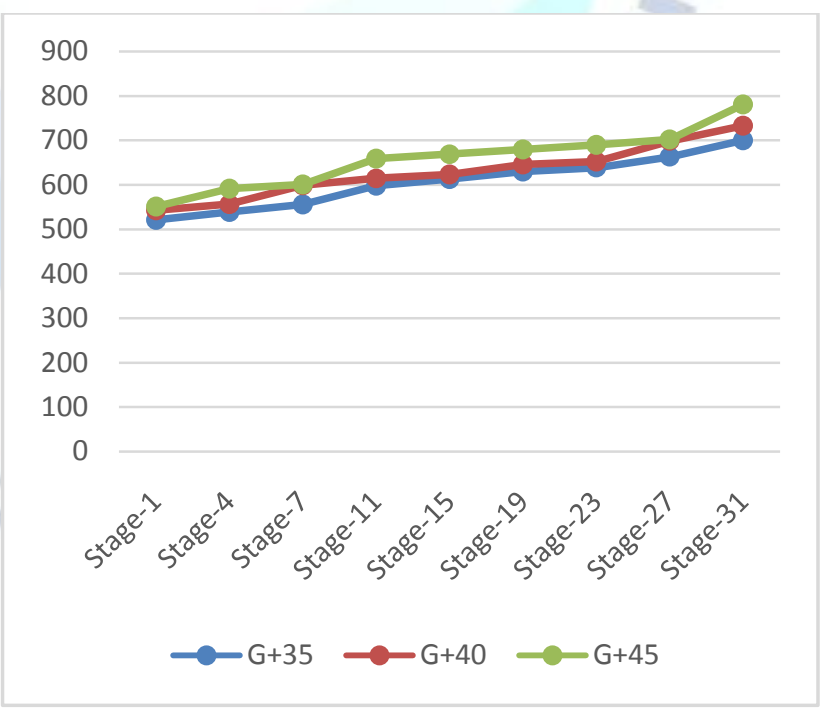

Fig-5: Shear Force Results of B-5 


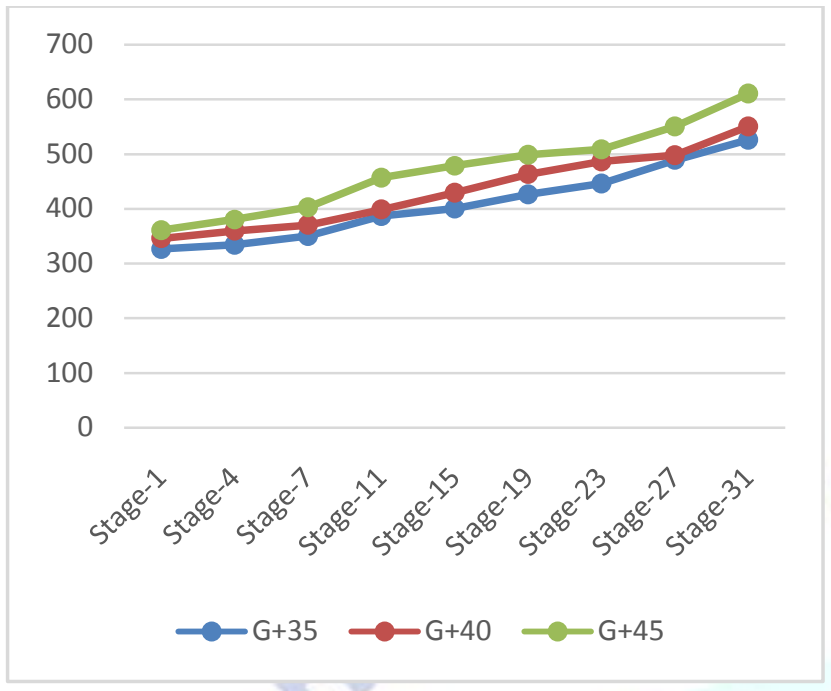

Fig-6: Shear Force Results of B-13

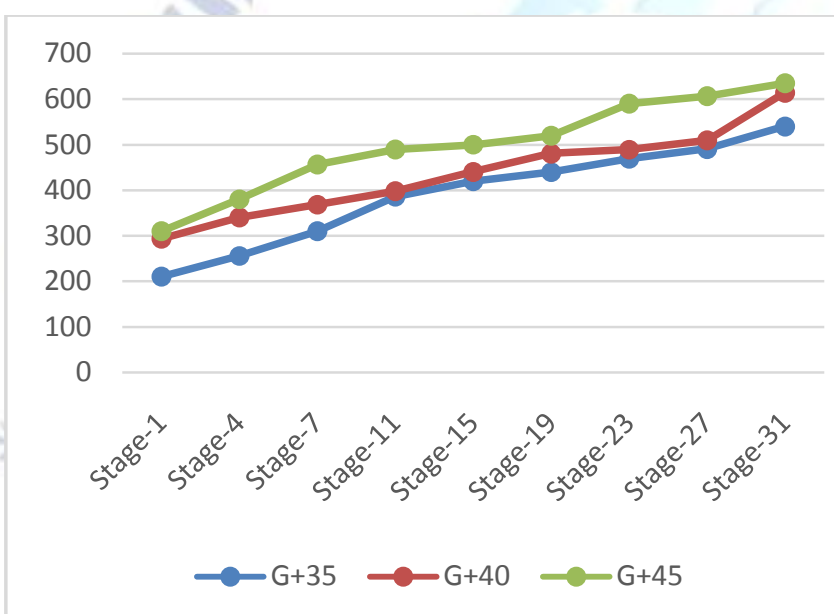

Fig-7: Shear Force Results of B-24

\section{Bending Moment Results of Columns:}

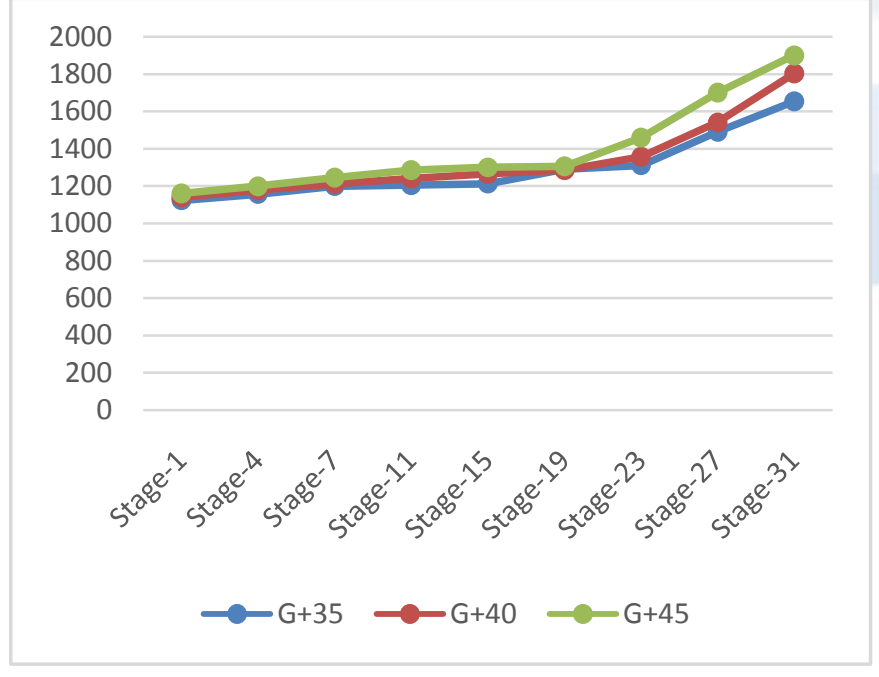

Fig-8: Bending Moment Results of C-1

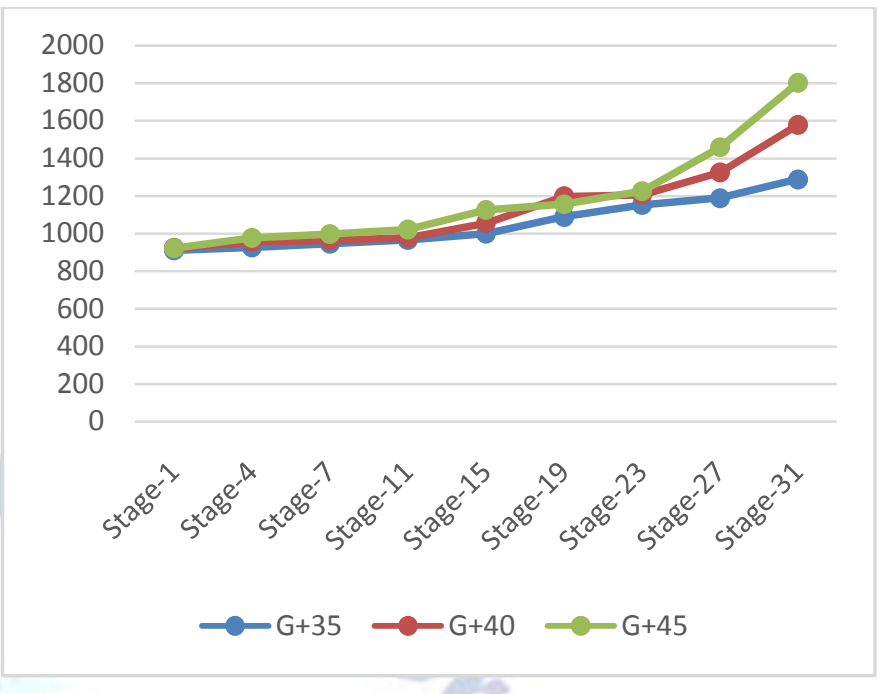

Fig-9: Bending Moment Results of C-7

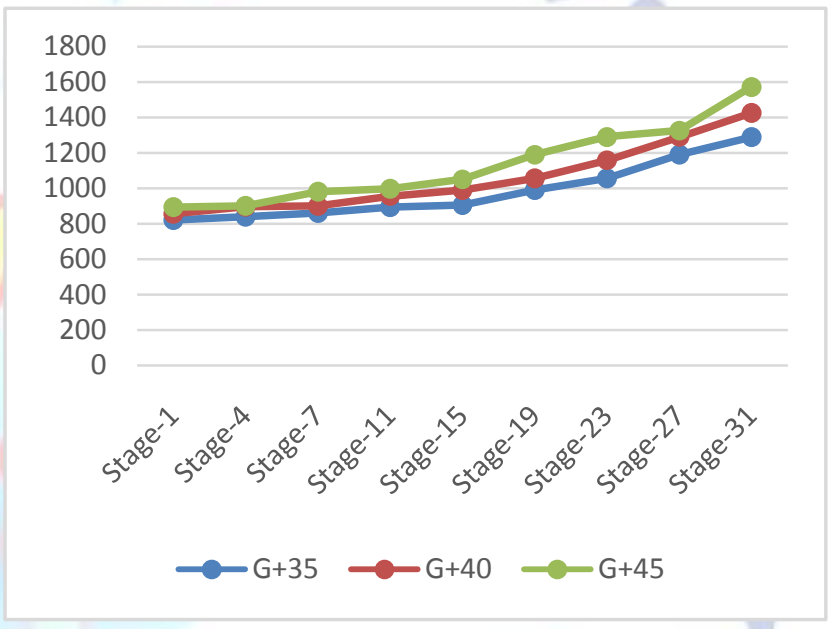

Fig-10: Bending Moment Results of C-12

\section{Shear Force Results of Columns:}

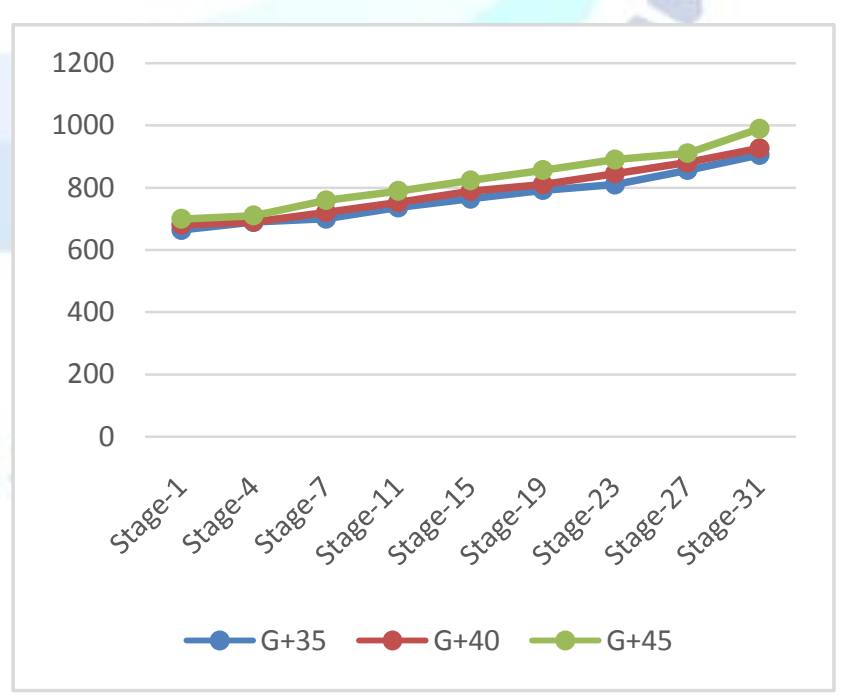

Fig-11: Shear Force Results of C-1 


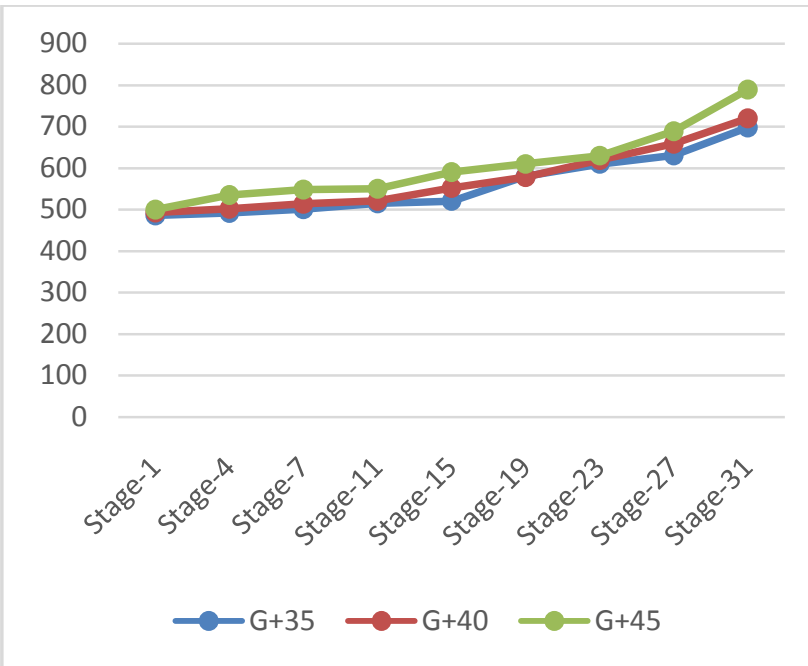

Fig-12: Shear Force Results of C-7

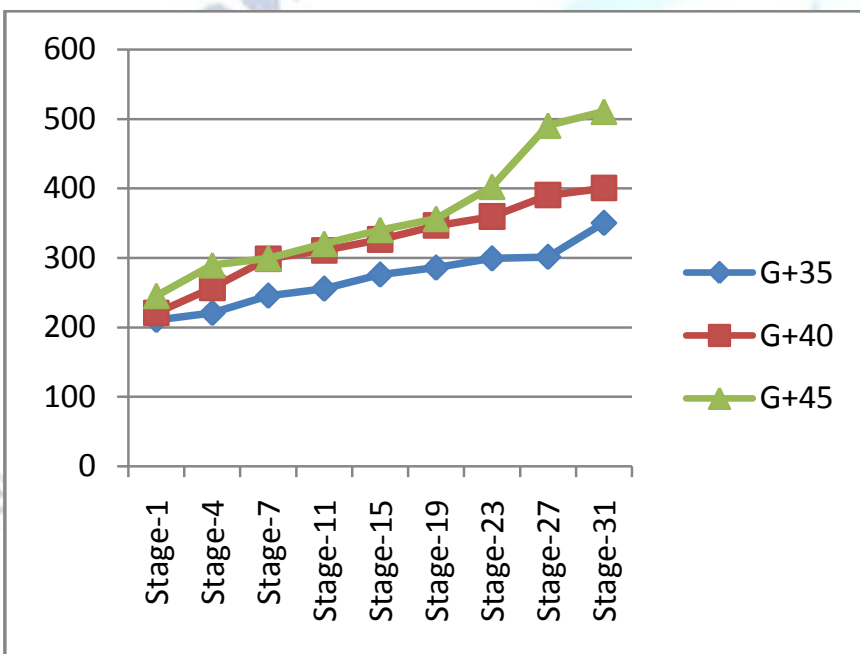

Fig-13: Shear Force Results of C-12

\section{Axial Force Results of Columns:}

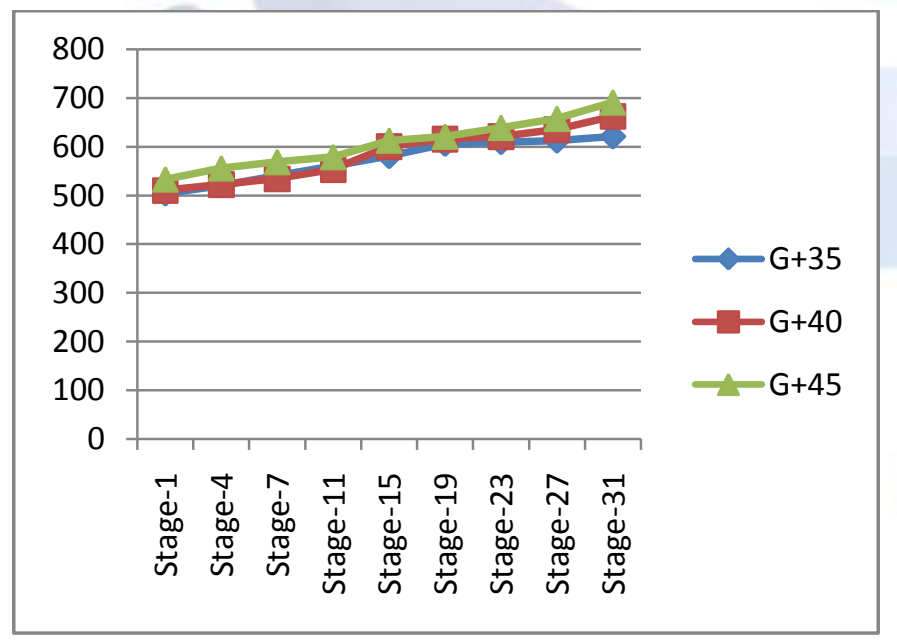

Fig-14: Axial Force Results of C-1

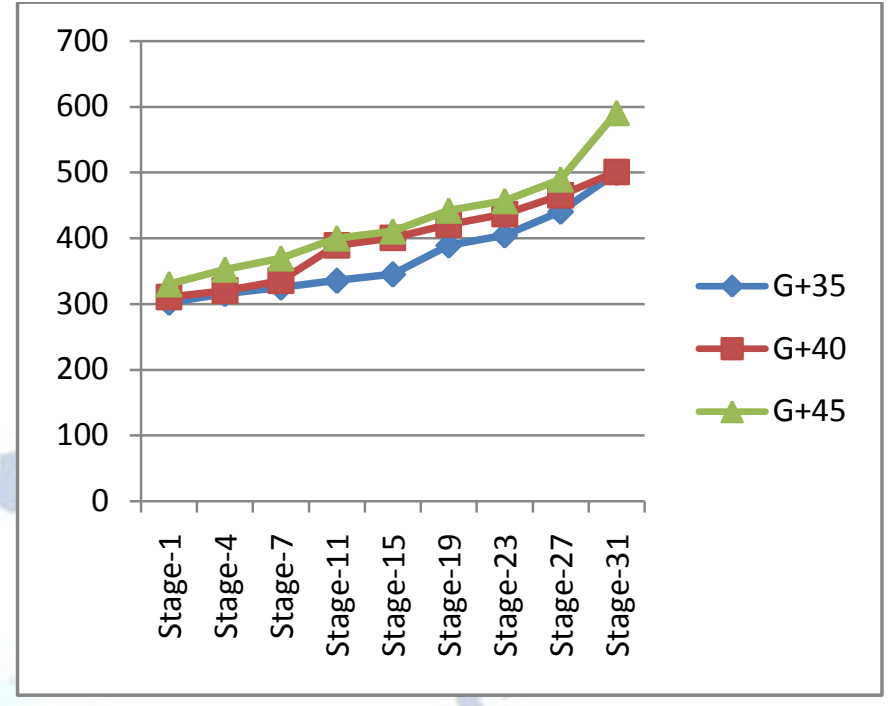

Fig-15: Axial Force Results of C-7

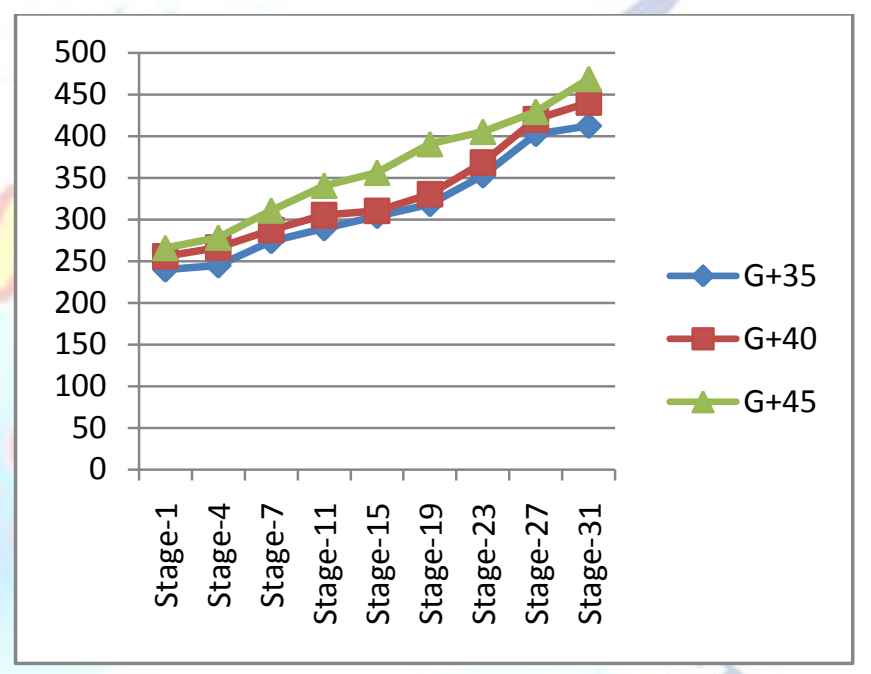

Fig-16: Axial Force Results of C-12

\section{Displacements of Structures:}

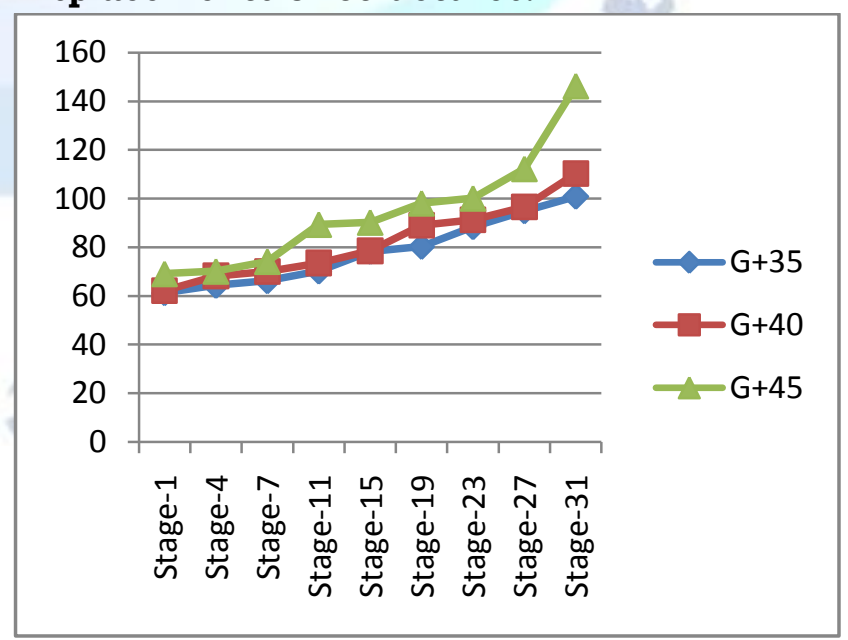

Fig-17: Displacements of Structures 


\section{VI.CONCLUSIONS}

It can be concluded from all the above observations that:

$>$ It is noticed that Displacements of Structures increase with increase in number of stories and also the Displacements of Structures are increases with stage by stage construction processes.

> In conventional analysis the load is applied only after modeling the entire structure. But the dead loads are of sequential nature in reality. So, from this we can conclude that conventional analysis is not enough to find out the actual behavior of structure.

$>$ From the results it is found that the variation of results is over estimated for upper floors and under estimated for lower floors.

$>$ The study reveals the necessity of performing nonlinear static analysis becomes important with increasing slenderness while each additional floor creates a significant load upon the columns.

$>$ It is evidenced that simulation of sequence of construction in the analysis leads to considerable variations in deformations and design forces obtained by conventional one step analysis.

$>$ After construction sequence analysis the structural displacements are within the limits. From this we conclude that the tube in tube structure gives better resistance to the external applied loads on it.

\section{REFERENCES}

[1] Analysis Of Multi-Storey Structures Using Sequential Analysis - A Review By Nikunj D. Banugariya

[2] Study And Comparison Of Construction Sequence Analysis With Conventional Lumped Analysis Using Etabs By R. Pranay

[3] Effect Of Sequential Construction On Multistoreyed Building By Dr.Suchita K. Hirde

[4] The Construction Stages Of The Six-Storey Residential Building In Saint-Petersburg By MariiaPanfilova

[5] Chronological Construction Sequence Effects On Reinforced Concrete And Steel Buildings By Yousuf Dinar

[6] Construction Sequence Analysis Of Multistoried RCC Building By Kiran Y. Naxane

[7] Importance Of Construction Sequence Analysis In Design Of High Rise Building By Santosh Panigrahi

[8] Analysis Of Multi Storied Rcc Building For Construction Sequence Loading By Sagupta R. A

[9] Construction Stage Analysis Of Flat Slab Structure With Respect To Non Linear Time History Analysis Using Software Aid By MitanKathrotiya, Amrut Manvai

[10] Optimum Positioning Of Outriggers To Reduce Differential Column Shortening Due To Long Term Effects In Tall Buildings by Kiran Kamath
[11] Study And Comparison Of Construction Sequence Analysis With Regular Analysis By Using Etabsby B Sri Harsha

[12] Construction Sequence Analysis Of Multi-Story Structures by K. Subramanian.

[13] IS 456 (2000) - "Plain and Reinforced Concrete - Code of Practice'.

[14] IS 1893(2000) Part I, 'Criteria for Earthquake Resistant Design of Structures', Part I, Bureau of Indian Standards, New Delhi, India.

[15] IS 875(Part 1) 1987 - "Code of Practice for Design Loads (Other than Earthquake) for buildings and Structures ", Part 1- Dead Loads

[16] IS 875(Part 2) 1987 - "Code of Practice for Design Loads (Other than Earthquake) for buildings and Structures ", Part 2-Imposed Loads

[17] IS 875(Part 3) 1987 - "Code of Practice for Design Loads (Other than Earthquake) for buildings and Structures “, Part 3- Wind Loads

[18] IS 800:2007 General Construction in Steel - Code of Practice
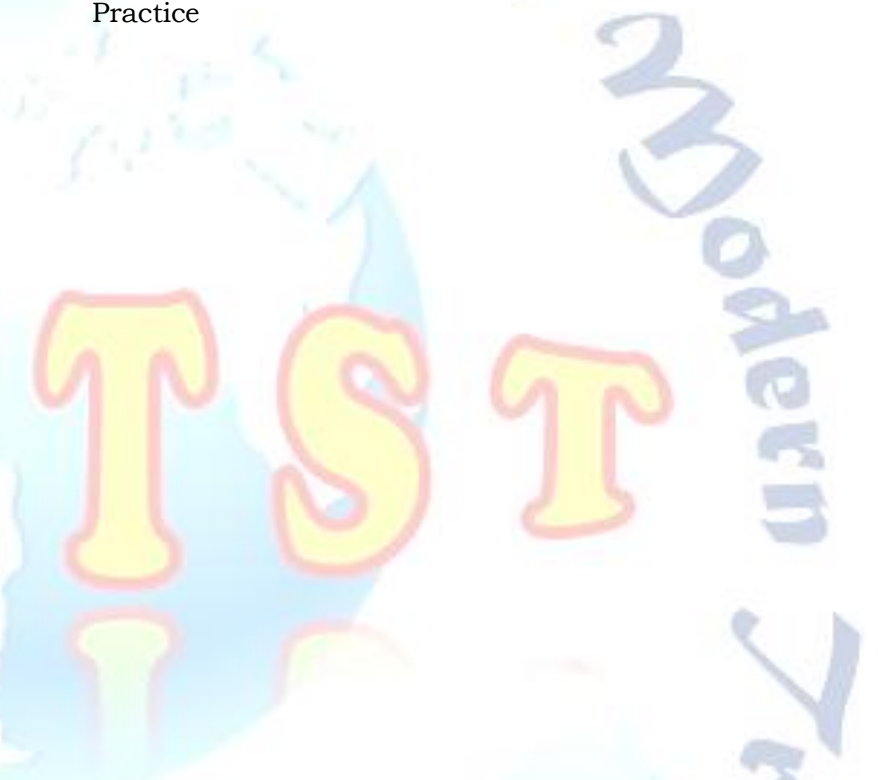

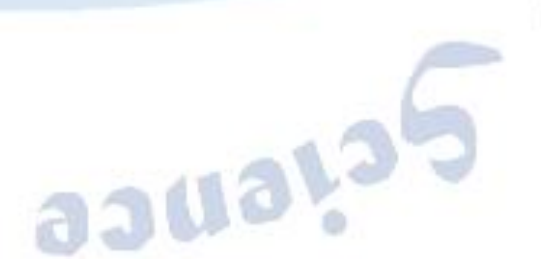

(n)

